\title{
UNSAFE SEXUAL BEHAVIOUR AMONG HIV-POSITIVE MSM PARTICIPATING IN COMMUNITY-BASED TREATMENT ADHERENCE PEER SUPPORT PROGRAM
}

\author{
Safirah Jaan Jaafar ${ }^{1,2}$, Khamisah Awang Lukman ${ }^{2 *}$, Nazarudin Safian ${ }^{1}$, Than Myint ${ }^{3}$, Swe ${ }^{2}$, Mohd Rohaizat \\ Hassan $^{1}$, Rosnah Sutan ${ }^{1}$, Wong Chin Mun ${ }^{1}$ and Mohammad Saffree Jeffree ${ }^{2}$ \\ ${ }^{1}$ Department of Community Health, Faculty of Medicine, Universiti Kebangsaan Malaysia, 56000 Cheras, \\ Kuala Lumpur, Malaysia. \\ ${ }^{2}$ Department of Community and Family Medicine, Faculty of Medicine and Health Sciences, University \\ Malaysia Sabah, 88400 Kota Kinabalu, Sabah, Malaysia. \\ ${ }^{3}$ Faculty of Health Sciences, STI Myanmar University, Yangon, Myanmar
}

*Corresponding author: Khamisah Awang Lukman

Email: khamisah@ums.edu.my

\begin{abstract}
This study aims to investigate the unsafe sexual behaviour among HIV-positive men who have sex with men (MSM) participating in community-based Treatment Adherence Peer Support Program (TAPS) based in Kota Kinabalu, Sabah. A cross-sectional study that involved 109 HIV-positive MSM was conducted using a validated questionnaire adapted from Integrated Biological and Behavioural Surveillance (IBBS) 2012, in two main languages which are Malay and English. ${ }^{1}$ This questionnaire contained information on socio-demographic factors, respondents' sexual history since they were diagnosed with HIV, and participation with community-based TAPS. Among the total 109 respondents, $62.4 \%$ had stated that they had practised unsafe sexual behaviour since they were diagnosed with HIV. Prevalence of self-reported Sexually Transmitted Infections (STIs) was $24.8 \%$. About $92.7 \%$ of participants were on highly active antiretroviral therapy (HAART) and had achieved $96 \%$ of compliancy. Prevalence of unsafe sexual behaviour differed significantly between respondents on HAART (66.3\%) compared to the non-HAART group $(12.5 \%)\left(x^{2}=7.005, p<0.01\right)$. Duration of last participation in the TAPS program significantly associated with unsafe sexual behaviour $\left(x^{2}=16.96, p<0.01\right)$. There is a high prevalence of unsafe sexual behaviour and self-reported STIs among HIV-infected MSM. Participation in TAPS resulted in a higher percentage of HAART coverage and the compliancy among the respondents; however, the prevalence of unsafe sexual behavioural remains high. The study findings highlight the importance of regular STls screening among HIV-infected MSM.
\end{abstract}

Keywords: Men who have sex with men (MSM), HIV-infected MSM, Treatment Adherence Peer Support Program (TAPS), unsafe sexual behaviour

\section{INTRODUCTION}

Since the beginning of the HIV infection epidemic, about 70 million people were already infected with 35 million deaths which led to around 36.5 million persons living with HIV (PLHIV) by end of $2015 .^{2}$ The first HIV case reported in Malaysia was in $1986 .{ }^{3}$ Since then, HIV has become a serious health problem and challenges for the country's development. ${ }^{3}$ At the beginning of the epidemic, the main mode of transmission for HIV was through injecting drugs such as Intravenous Drug User (IVDU). ${ }^{4}$ Hence, early screening for HIV focused more on prisoners and drugs rehabilitation centre. $^{4}$

Malaysia was estimated to have 91,848 PLHIV at the end of 2015. ${ }^{5}$ Throughout the years, Malaysia has achieved a significant level of advancement in biomedical and behavioural modification which led to reducing the numbers of PLHIV to almost half from 28.4 to 11.7 cases per 100,000 populations in 2014. ${ }^{5}$ However, the trend of HIV mode of transmission has changed from injecting drugs to sexual activities especially homosexual and bisexual. The key populations (KP) that pose the infection rate of HIV above $5 \%$ include transgender (TG), male who have sex with male and female sex workers (FSW). ${ }^{6}$ In estimation, 173,000 MSM living in Malaysia with the prevalence of HIV infection at $7 \%$. Hence, as the transmission trend of HIV among MSM is increasing to $19 \%$, effective and efficient responses to minimize the risk and outcomes associated with HIV infection amongst MSM need to be taken seriously and urgently. ${ }^{6}$ Studies carried out among MSM discovered that there were a few significant factors which influenced HIV transmission. Reduction in the self-esteem and increment in the sexual compulsivity will affect MSM to engage in unsafe sexual behaviour. ${ }^{7}$ The pattern among MSM with multiple sexual partners and inconsistent condom use contributes to the increasing trend on the prevalence of HIV infection among MSM. ${ }^{7}$

In Sabah, the prevalence of HIV among MSM in 2012 was $1.3 \%$ but subsequently, it went up to $3.1 \%$ within two years in $2014 .{ }^{1}$ During the same period, the percentage of condom use among MSM was also in a decreasing trend from $72.5 \%$ to $46.2 \%{ }^{8}$ The percentage of MSM who tested for HIV and knew their status have also decreased from $55.4 \%$ to $33.7 \% .{ }^{8}$ All these trends contribute to the increasing of the prevalence of HIV among MSM. ${ }^{5}$ 
Due to the stigmatization and disclosure of the sexual preferences among MSM, their population can be better approached by the communitybased support. In an effort to improve linkages to care and health services and adherence to antiretroviral therapy (ART), Treatment Adherence Peer Support Program has been established (previously Hospital Peer Support Program). This program envisaged that early exposure of HIV infection coupled with information and education about antiretroviral treatment and adherence, emotional management, and healthy living with HIV could mark a decrease onward HIV transmission. ${ }^{8}$ The Treatment Adherence Peer Support Program (TAPS) aims to improve treatment adherence among PLHIV on Highly Active Antiretroviral Therapy (HAART) by providing information regarding treatment adherence and psychosocial support. ${ }^{9}$ TAPS programs will give the latest information regarding HIV/AIDS, safe sex practices, nutrition, and offer positive support to their new clients with HIV/AIDS. Therefore, it is anticipated that this study can investigate and assess the unsafe sexual behaviour among HIVpositive MSM participating in community-based TAPS based in Kota Kinabalu, Sabah.

\section{METHODS}

This cross-sectional study involved a total of 109 respondents in Kota Kinabalu, Sabah. They were homosexual or bisexual men with HIV-positive status, aged 18 years old and above, and were registered with community-based TAPS based in Kota Kinabalu, Sabah. A questionnaire was designed based on IBBS 2012 and 2014, but it was translated and adapted for socio-demographic competence in Sabah. ${ }^{1}$ A closed ended questionnaire with face-to-face interview was conducted by trained interviewers from community-based volunteers. This questionnaire contained five sections. The first section was on socio-demographic factors such as age, marital status, education level, profession, and monthly income. The second section was respondent's sexual history since they were diagnosed with HIV. Unsafe sexual behaviours include practising unprotected sex, inconsistent condom use, having sexual intercourse with an HIV-positive partner, or having multiple sexual partners including casual partners and practising group sex even after diagnosed with HIV. The third section of the questionnaire was on the HAART coverage and compliancy. The fourth section was about the sexually transmitted infections (STIs) since diagnosed with HIV. The fifth section was on their engagement with community-based support programs. From the second till the fifth section of the questionnaire, questions were regarding the respondent's history since they had been diagnosed with HIV. Data were analysed using SPSS Version 22.0. Both descriptive and inferential statistical methods were used. Univariate and bivariate analysis $\left(\mathrm{x}^{2}\right)$ were carried out with $p$-value significant if $p<0.05$. This study obtained ethical clearance from the University
Malaysia Sabah Medical Ethic Research Committee - JKEtika 1/17(6). The study purposes were explained to each participant. A consent form written in two languages: in English and Malay, was provided to the participants and the participants were ensured to understand the contents of the consent form before giving their approvals.

\section{RESULTS}

In this study, the age range of the 109 respondents was from 18 to 54 , with $63.3 \%$ was from 26 to 40 years old. Half of the respondents acquired tertiary educational level and majority of them were unmarried, while others were either divorced, separated, or staying with a male partner. More than half of the respondents reported they practised unsafe sexual behaviour including unprotected sex, inconsistent condom use, having sexual intercourse with an HIVpositive partner, or having multiple sexual partners including casual partners, and practising group sex even after diagnosed with HIV. A majority of the HIV-positive MSM were homosexual (75.2\%) and bisexual (24.8\%). Few of them never had sex since they had been diagnosed with HIV (26.6\%). About $71.3 \%$ reported having permanent partners, with $42.1 \%$ of their permanent partners as HIV carrier too. Among the high-risk group, $36.8 \%$ continued to have sexual relationship with HIV-negative partners, while the other $21.1 \%$ were not aware of their permanent partners' HIV status. Out of the total of 109 respondents, $24.8 \%$ had been diagnosed with STIs. Most frequent symptoms found among the participants were dysuria, followed by penile ulcer and anal ulcer.

The age group of the respondents was significantly associated with sexual behaviour, as $83.3 \%$ of the MSM involved in unsafe sexual behaviour were between 35 to 44 years old. Even though the association between marital status and unsafe sexual behaviour was insignificant, the result showed that all the married MSM were practising unsafe sexual behaviour. About $92.7 \%$ of the respondents were already on HAART; which showed $96 \%$ of compliancy was achieved. For those MSM diagnosed with HIV but not on HAART, most of them were in the process of physician consultation and some opted for alternative treatment. The reasons for non-compliance to HAART were reported as loss of interest with the treatment despite explained properly about the objectives of the treatment by physician. The prevalence of unsafe sexual behaviour differed significantly between respondents on HAART (66.3\%) compared to the non-HAART group (12.5\%) $\left(x^{2}=7.005, p<0.01\right)$ which means that taking HAART has significant association with unsafe sexual behaviour. TAPS program was organized by volunteers of a community organisation based in Kota Kinabalu. All participants were recruited by medical personnel referral, approached by community volunteers, introduced by friends, and via social media. The reasons of enrolment into 
this community-based HIV intervention program were reported as due to medical personnel's influence, program staff's (volunteers) influence, peer influence, and the respondents' intention for seeking support and counselling. Almost $80 \%$ of the respondents had registered under TAPS for more than 12 months. Among all respondents, $52.3 \%$ have mentioned that the topic discussed in the program included the treatment adherence for HAART. Around $51.4 \%$ of the respondents have last participated in the group discussion by TAPS program coordinator within 12 months and below, while $12.8 \%$ have participated in more than 12 months ago. Almost all (92.9\%) who have participated in TAPS programs for more than one year ago were engaged in unsafe sexual behaviour. Even among the HIV-positive MSM participants who have just attended TAPS program in the last three to six months, only half of them (45.2\%) refrained from unsafe sexual behaviour practise, which is not much of a difference from those who have never attended any TAPS programs (51.3\%). The association of duration since last TAPS participation against unsafe sexual behavioural practice is significant $(x 2=16.96, p<0.01)$.

Table 1. Socio-demographic factors, characteristics of sexual behaviour and self-reported STls

\begin{tabular}{|c|c|c|}
\hline Characteristic & n (\%) & Mean \\
\hline Age (year) & & 33.6 \\
\hline \multicolumn{3}{|l|}{ Marital Status } \\
\hline Married & $3(2.8)$ & \\
\hline Unmarried & $101(92.7)$ & \\
\hline Divorced & $3(2.8)$ & \\
\hline \multicolumn{3}{|l|}{ Nature of Job } \\
\hline Professional & $12(11.0)$ & \\
\hline Non-Professional & $42(38.5)$ & \\
\hline Self Employed & $33(30.3)$ & \\
\hline Unemployed & $18(16.5)$ & \\
\hline Student & $4(3.7)$ & \\
\hline \multicolumn{3}{|l|}{ Unsafe Sex } \\
\hline Yes & $68(62.4)$ & \\
\hline No & $41(37.6)$ & \\
\hline \multicolumn{3}{|l|}{ Sexual Orientation } \\
\hline Homosexual & $82(75.2)$ & \\
\hline Bisexual & $27(24.8)$ & \\
\hline \multicolumn{3}{|c|}{ Had sex after diagnosed HIV } \\
\hline Yes & $80(73.4)$ & \\
\hline No & $29(26.6)$ & \\
\hline \multicolumn{3}{|c|}{ Had male permanent partner $(\mathrm{N}=80)$} \\
\hline Yes & $57(71.3)$ & \\
\hline No & $23(28.7)$ & \\
\hline \multicolumn{3}{|c|}{ Male Permanent Partner HIV status $(\mathrm{N}=57)$} \\
\hline Positive & $24(42.1)$ & \\
\hline Negative & $21(36.8)$ & \\
\hline Don't know & $12(21.1)$ & \\
\hline \multicolumn{3}{|c|}{ Condom use with permanent partner $(\mathrm{N}=57)$} \\
\hline Yes & $20(35.0)$ & \\
\hline No & $37(65.0)$ & \\
\hline \multicolumn{3}{|c|}{ Had male casual partner(s) $(\mathrm{N}=80)$} \\
\hline Yes & $30(37.5)$ & \\
\hline No & $50(62.5)$ & \\
\hline \multicolumn{3}{|c|}{ Condom use with casual partner(s) $(\mathrm{N}=30)$} \\
\hline Yes & $20(66.7)$ & \\
\hline No & $10(33.3)$ & \\
\hline \multicolumn{3}{|c|}{ Engaged in group sex $(\mathrm{N}=80)$} \\
\hline Yes & $12(15.0)$ & \\
\hline No & $68(85.0)$ & \\
\hline \multicolumn{3}{|c|}{ Sexually Transmitted Diseases } \\
\hline Yes & $27(24.8)$ & \\
\hline No & $82(75.2)$ & \\
\hline \multicolumn{3}{|l|}{ STIs Symptoms $(\mathrm{N}=27)$} \\
\hline Dysuria & $17(15.6)$ & \\
\hline Penile ulcer & $9(8.3)$ & \\
\hline Anal ulcer & $5(4.6)$ & \\
\hline Urethral discharge & $4(3.7)$ & \\
\hline Anal discharge & $2(1.8)$ & \\
\hline
\end{tabular}


Table 2. Characteristic related to unsafe sexual behaviour

\begin{tabular}{|c|c|c|c|c|}
\hline & Unsafe Sex & our, n (\%) & & \\
\hline Characteristic & Yes & No & $x^{2}$ & $p$ \\
\hline Age $\left(\right.$ year) ${ }^{\#}$ & & & 11.15 & $0.01^{*}$ \\
\hline 18 to 24 & $8(57.1)$ & $6(42.9)$ & & \\
\hline 25 to 34 & $24(49.0)$ & $25(51.0)$ & & \\
\hline 35 to 44 & $30(83.3)$ & $6(16.7)$ & & \\
\hline 45 to 54 & $6(60.0)$ & $4(40.0)$ & & \\
\hline Marital Status ${ }^{\#}$ & & & 2.80 & 0.74 \\
\hline Married & $4(100)$ & $0(0.0)$ & & \\
\hline Unmarried & $62(60.8)$ & $40(39.2)$ & & \\
\hline Divorced & $2(66.7)$ & $1(33.3)$ & & \\
\hline Nature of Job & & & 5.38 & 0.15 \\
\hline Professional & $5(41.7)$ & $7(58.3)$ & & \\
\hline Non-Professional & $28(66.7)$ & $14(33.3)$ & & \\
\hline Self Employed & $24(72.7)$ & $9(27.3)$ & & \\
\hline Unemployed & $11(50.0)$ & $11(50.0)$ & & \\
\hline On HAART & & & 9.16 & $0.00^{*}$ \\
\hline Yes & $67(66.3)$ & $34(33.7)$ & & \\
\hline No & $1(12.5)$ & 7 (87.5) & & \\
\hline Non-compliant $^{\#}(\mathrm{~N}=101)$ & & & 1.23 & 0.38 \\
\hline Yes & $3(75.0)$ & $1(25.0)$ & & \\
\hline No & $64(65.9)$ & $33(34.1)$ & & \\
\hline $\begin{array}{l}\text { Last participation TAPS } \\
\text { program (months) }\end{array}$ & & & 16.96 & $0.00^{\#}$ \\
\hline 3 to 6 & $14(45.2)$ & $17(54.8)$ & & \\
\hline 6 to 12 & $21(84.0)$ & $4(16.0)$ & & \\
\hline$>12$ & $13(92.9)$ & $1(7.1)$ & & \\
\hline Never Participate & $20(51.3)$ & $19(48.7)$ & & \\
\hline
\end{tabular}

"Significant level at $p<0.05, \mathrm{x}^{2}$ test, "Significant level at $p<0.05$, Fisher exact test

\section{DISCUSSION}

The age of the respondents presented a significant association with sexual behaviour. Majority of the respondents aged between 35 to 44 were involved in unsafe sexual behaviour. The obtained result of the age distribution is quite different from that of Thailand's, where the majority of MSM was below 29 years old. ${ }^{10}$ The age distribution of MSM in Thailand is younger than in Malaysia and it might be due to the advancement in tourism and entertainment sectors in Thailand. Half of the respondents had acquired tertiary educational level. The finding is similar to a study conducted in China, where $48.2 \%$ of the MSM had reached college or university level of tertiary education. ${ }^{11}$ Furthermore, the total employment (79.8\%) is higher than in the United States of America (63.9\%) and lower than South Africa (88.3\%). ${ }^{12}$ Most of the HIV-positive MSM were unmarried, while others were either divorced, separated, or staying with a male partner. The main reasons for getting married were reported as to satisfy their parents' request and to have their own children. Even though the association between marital status and unsafe sexual behaviour is insignificant, the result shows that all of those who were married involved in unsafe sexual behaviour. The prevalence of unsafe sexual behaviour among HIV-positive MSM in Sabah is considerably quite high when compared with the prevalence of unsafe sexual behaviour concluded via meta-analysis done in the USA (43\%). ${ }^{13}$ It might be due to the lack of awareness and lack of perceived severity living with HIV, perceived possibility to be re-infected with another strain of HIV, and perceived risk of infected with STIs. Thus, further research on their perception towards HIV and unsafe sexual behaviour should be done. A specific health awareness program also should be given in promoting better awareness about HIV and importance of practicing safer sexual behaviour among HIV positive MSM.

As for the STIs prevalence among HIV-positive MSM in Sabah, the percentage is $24.8 \%$ and similar to $21.8 \%$ of STIs prevalence among HIV-positive MSM in the USA. ${ }^{14}$ The high percentage in HAART coverage and compliancy among the respondents can be due to the participation in the TAPS programs. The study results indicate the similar prevalence of unsafe sexual behaviour practice among those who have just attended TAPS program in the past three to six months and those who have never attended TAPS.

\section{CONCLUSION}

There is a high prevalence of unsafe sexual behaviour and self-reported STIs among the HIVpositive MSM. The participation in TAPS resulted 
in a higher percentage of HAART coverage and the compliancy among the respondents; however, the prevalence of unsafe sexual behavioural remains high. The community-based TAPS should highlight the importance of regular STls screening and strengthening the program on behavioural risk assessment among HIV-positive MSM on HAART in Sabah.

\section{ACKNOWLEDGEMENT}

We gratefully acknowledge the Faculty of Medicine and Health Sciences, Universiti Malaysia Sabah for approving research grant (GUG0142$1 / 2017$ ) to conduct this study. We also would like to thank and acknowledge KASIH(NGO) and all the respondents who participated in this study.

\section{Conflict of interest}

The authors declare no potential conflict of interest.

\section{REFERENCES}

1. Anita Suleiman SN, Teh Yik Koon, Noorhaida Ujang, Muhammad Amir Kamaluddin. INTEGRATED BIOLOGICAL \& BEHAVIOURAL SURVEILLANCE SURVEY. 2012.

2. UNAIDS GA. Global AIDS update 2016. Geneva, Switzerland: World Health Organization Library. 2016.

3. Huang $M$, Hussein $\mathrm{H}$. The HIV/AIDS epidemic country paper: Malaysia. AIDS Education and Prevention. 2004; 16(Supplement A):100-109.

4. Jürgens R, Ball A, Verster A. Interventions to reduce HIV transmission related to injecting drug use in prison. The Lancet infectious diseases. 2009; 9(1):57-66.

5. SECTION HS, Division DC, Malaysia MoH. Global AIDS Response Progress Report Malaysia. 2015.

6. Barmania S, Aljunid SM. Navigating HIV prevention policy and Islam in Malaysia: contention, compatibility or reconciliation? Findings from in-depth interviews among key stakeholders. BMC Public Health. 2016; 16(1):524.
7. Benotsch EG, Kalichman SC, Kelly JA. Sexual compulsivity and substance use in HIVseropositive men who have sex with men: Prevalence and predictors of high-risk behaviors. Addictive behaviors. 1999; 24(6): 857-868.

8. National Strategic Plan On HIV And AIDS. National Strategy on HIV and AIDS 2011 - 2015. 2015.

9. World Health Organization. Global HIV/AIDS response: epidemic update and health sector progress towards universal access: progress report 2011. Global HIVIAIDS response: epidemic update and health sector progress towards universal access: progress report 2011. 2011(1).

10. van Griensven F, Varangrat A, Wimonsate W, et al. Trends in HIV prevalence, estimated HIV incidence, and risk behavior among men who have sex with men in Bangkok, Thailand, 2003-2007. JAIDS Journal of Acquired Immune Deficiency Syndromes. 2010; 53(2):234-239.

11. Feng $\mathrm{Y}, \mathrm{Wu} Z$, Detels $\mathrm{R}$, et al. HIV/STD prevalence among MSM in Chengdu, China and associated risk factors for HIV infection. Journal of acquired immune deficiency syndromes (1999). 2010; 53(Suppl 1): S74.

12. Wagenaar BH, Sullivan PS, Stephenson R. HIV knowledge and associated factors among internet-using men who have sex with men (MSM) in South Africa and the United States. PloS one. 2012; 7(3):e32915.

13. Crepaz N, Marks G, Liau A, et al. Prevalence of unprotected anal intercourse among HIVdiagnosed MSM in the United States: a metaanalysis. Aids. 2009; 23(13):1617-1629.

14. Hoover KW, Butler M, Workowski K, et al. STD screening of HIV-infected MSM in HIV clinics. Sexually transmitted diseases. 2010; 37(12): 771-776. 